\title{
Herramientas digitales on line al servicio de los procesos de aprendizaje: comunicación, motivación y emociones.
}

\author{
AUTORA: \\ Dra. Núria Puig Borràs \\ Universitat de Girona
}

Palabras clave: aprendizaje, comunicación, emociones, digital, educación online, apps, blogs, plataformas digitales, redes sociales.

En este artículo de divulgación se relatan algunas experiencias educativas a través del uso de herramientas digitales para mejorar el nivel de comunicación y los procesos de aprendizaje después de la irrupción forzosa del on-line provocada por el estallido de la pandemia y sus consecuencias en la educación universitaria a partir de marzo de 2020.

El uso de estas herramientas digitales ya era habitual en la asignatura de Creatividad, de los estudios de Publicidad y relaciones públicas; y también en la asignatura de Cultura visual y medios de Comunicación del Grado de Diseño y Desarrollo de Videojuegos, ambas de la Universitat de Girona. No obstante, ahora estas herramientas han ganado protagonismo.

En la educación a distancia, cuando es escogida como una opción se asumen unas reglas de juego comunicativo que llevan implícitas unas ventajas y unos inconvenientes. La educación a distancia como elección viene a dar respuesta a una serie de necesidades del estudiante que opta por esta fórmula. A veces, es una buena opción para llegar a todos los rincones del planeta, o al menos a todos aquellos que no se ven afectados por la brecha digital.

No obstante, cuando la educación a distancia se produce de forma forzada en un momento determinado, como ha ocurrido con la pandemia, plantea retos de forma súbita. En los estudios de comunicación siempre hemos trabajado formas de comunicación mediada. Partimos pues de una ventaja. El estudio y el uso de los medios de comunicación de masas y las redes sociales forman parte de nuestro objeto de estudio y de nuestras herramientas de trabajo. 
NÚRIA PUIG BORRÀS: Herramientas digitales on line al servicio de los procesos de aprendizaje: comunicación, motivación y emociones.

En educación es preciso siturar el foco en el alumno y en el aprendizaje. Ello implica poner al alumno en el centro de nuestro interés, de la misma forma que lo hacíamos en un contexto presencial. Implica preguntarnos cómo aprende, cómo enfrenta una situación nueva para todos, cómo es el contexto en el que realiza el aprendizaje y cómo afecta esta nueva situación a sus motivaciones y sus emociones.

Como dice Mena-Young en un artículo publicado en la revista Communication Papers: "El aprendizaje virtual entonces no puede ser solamente una traslación del contenido de un curso presencial a uno mediante entorno en internet, sino que implica una reconstrucción completa que, en la actualidad, implica pensar en los entornos responsive, que impulsan el aprendizaje ubicuo. En este modelo las prácticas educativas están mediadas por tecnologías móviles y apoyadas en dispositivos convergentes. La finalidad de esas prácticas es que los estudiantes sean capaces de aprender en cualquier lugar, con independencia de su localización o la disposición de recursos y materiales físicos (Sevillano y Vásquez citando a Drent y Meelissen, 2013, p. 35)." (MENA-YOUNG, 2018, p.109)

Más allá de la tecnología y de las herramientas disponibles, que afortunadamente han sido muchas, debemos poner todo el empeño en utilizar estas herramientas para mejorar el nivel de comunicación entre todos los miembros de esta aula virtual. Con el objetivo, entre otros, de mejorar los niveles de motivación y generar las emociones que propician los procesos de aprendizaje. Y más allá de todo esto cuidarnos los unos a los otros. Detectar flaquezas para ayudarnos entre nosotros y conseguir que nadie se vea abocado al abandono. Aprendemos juntos y esto solamente es posible si cuidamos los canales de comunicación, aquellos que influyen en nuestras emociones y nuestra motivación hacia el aprendizaje. Todo ello va mucho más allá de la traslación de contenido, pero no hay que perder de vista el contenido de las asignaturas que es, como diría Arguiñano, el fundamento. No obstante, si no se dan las condiciones emocionales y comunicativas adecuadas no hay forma de transmitir, ni de acceder a los contenidos.

En la definición de la comunicación de masas se dice que la comunicación mediada se produce a través de un elemento técnico entre el emisor y el receptor. Hay siempre una distancia física entre ambos y existe también una "distancia perceptiva". El verdadero reto es que esta distancia perceptiva no se traduzca en ineficacia comunicativa. Otra cosa será qué preferimos, qué nos gusta más, o qué nos hace más felices. Posiblemente prefiera los debates cara a cara con los alumnos, casi añoro tener que decir "por favor, por favor no hablemos todos a la vez". Con el tiempo, han surgido en nuestra aula virtual algunas fórmulas on line dirigidas hacia la socialización. Por ejemplo, lo que denomino los "pasillos virtuales", que no es más que quedarse a hablar un ratito después de la sesión de clase, mejorando así los niveles de comunicación entre los miembros del aula. Lo que antes hacíamos de forma natural en el pasillo o en el bar de la facultad. Hechos que por sencillos no son carentes de valor.

A continuación, expondré algunas herramientas utilizadas con el objetivo de mejorar los procesos de aprendizaje. El uso de blogs, plataformas digitales, portafolios digitales y redes sociales no es nada extraño en los procesos de aprendizaje de las asignaturas que desarrollo en la universidad. Estas asignaturas son "Creatividad" en los estudios de Publicidad y relaciones públicas y "Cultura visual y medios de comunicación" en los estudios de Diseño y desarrollo de videojuegos. En estas asignaturas se practica la creación de contenidos para medios digitales y utilizamos de forma habitual aplicaciones de diversa índole. La importancia de la creación, difusión y consumo de contenidos a través de medios y aplicaciones digitales no era menor en tiempos de prepandemia. No obstante, nos vimos obligados a sustituir todas 
NÚRIA PUIG BORRÀS: Herramientas digitales on line al servicio de los procesos de aprendizaje: comunicación, motivación y emociones.

las formas de comunicación entre los alumnos y el profesor por herramientas que afortunadamente no nos eran para nada desconocidas.

Además de redirigir las clases hacia entornos digitales y proporcionar materiales de estudio, mi preocupación se centró también en la formulación de propuestas que potenciaran la comunicación entre los miembros de la clase. A pesar que las formas de comunicación mediada son casi inherentes y necesarias en los perfiles profesionales de ambos estudios, surgen carencias que pueden llevar al alumno a la desmotivación e incluso al abandono. Des del punto de vista docente, la presencialidad permite captar sensaciones y estados de ánimo de los alumnos de forma muy efectiva. En el proceso de aprendizaje entran en juego muchas cosas más que la transmisión de conocimientos o la experimentación enfocada a los aprendizajes. Hay además un entramado emocional y motivacional que nos predispone a aprender. En la presencialidad el profesor puede detectar mejor los frenos e intervenir, paliando los posibles problemas que pueden hacer menos efectivo el proceso de aprendizaje. Que duda cabe que las buenas emociones facilitan el aprendizaje, ponen en funcionamiento resortes relacionados con la atención, la cognición y la memoria.

Hay que confiar en la capacidad de aprendizaje del alumnado, confiar en su implicación en el aprendizaje. Cuando confían en nosotros, nos hacemos más responsables. $Y$ es necesario responsabilizarnos de nuestros propios procesos de aprendizaje. Sin embargo, en este contrato implícito entre alumnado y profesorado, este último tiene la función de guiar estos procesos, y la responsabilidad de detectar y corregir, en la medida de lo posible, las flaquezas que pueden llevar a los alumnos al fracaso en la asignatura o en sus estudios.

La figura del docente no es tan importante y en todo caso hay que redefinirla. Los alumnos aprenden también sin la intervención del profesor. Sugata Mitra en sus experimentos de autoaprendizaje o en sus reflexiones en Beyond the Hole in the wall o en The school in the cloud redefine el papel del profesor. Sugata Mitra dice sobre el proceso de aprendizaje en el alumnado infantil: "Los niños pueden aprender cualquier cosa por sí mismos si pueden acceder a internet en grupo. De hecho, es muy posible que el «aprendizaje» tradicional ya no sea tan importante como lo era antes." (SUGATA MITRA, 2021, pág 53). Su primer experimento llamado "El agujero en la pared", desarrollado en los barrios pobres de Delhi, data de 1999. Con ello quiero remarcar que el papel del profesor y el uso de las herramientas digitales en los procesos de aprendizaje forman parte de las reflexiones y las adaptaciones que los docentes ya venimos haciendo desde hace mucho tiempo.

Es necesario destacar que en niveles inferiores de educación se dan más fácilmente problemas producidos por la brecha digital que en los alumnos de nivel universitario y más concretamente de estos grados. Si bien, en estos últimos se pueden dar casos puntuales de problemas de acceso a conexiones o aparatos tecnológicos, no es lo más habitual. Sin embargo, estas carencias propias de la brecha digital pueden ser un problema más extendido en algunos alumnos de primaria, secundaria o formaciones profesionales. En estos casos, habría que solucionar en primer lugar este problema de base para garantizar el acceso a la educación de todos.

A continuación veremos algunas herramientas digitales de creación y difusión de contenidos utilizadas en las dos asignaturas anteriormente mencionadas. 
NÚRIA PUIG BORRÀS: Herramientas digitales on line al servicio de los procesos de aprendizaje: comunicación, motivación y emociones.

\section{Las asignaturas de Creatividad y de Cultura visual y medios de comunicación.}

En estas dos asignaturas la necesidad de trabajar on-line de forma repentina nos ha sorprendido con muchísimas herramientas digitales y con habilidades suficientes para utilizarlas. A mi entender, el mayor hándicap no radica en la falta de herramientas sino en la calidad de las comunicaciones. Con todas estas herramientas podíamos crear y difundir contenido. Pero también se hacía necesario, como he expresado anteriormente, el cuidado de la motivación y las emociones de todos nosotros. Debíamos mantener la determinación de seguir trabajando de forma motivada y efectiva, no solamente para el proceso de aprendizaje y la obtención de competencias, sino también para mantener el hilo de comunicación necesario para establecer un buen marco emocional y motivacional de aprendizaje.

El primer confinamiento, inesperado y contundente, nos llega trabajando en la asignatura de "Cultura visual y medios de comunicación" con los estudiantes de la Escuela Superior Politécnica del Grado de Diseño y Desarrollo de Videojuegos. Esta asignatura se hace en primero. Un dato a tener en cuenta, ya que no tienen del todo forjado el entramado relacional que establecemos en la universidad.

En este contexto, utilizamos YouTube para hacer llegar algunas explicaciones de contenidos de la asignatura y pusimos en marcha un blog colaborativo. Se trataba de conseguir una plataforma para trabajar "juntos". Muchos de los alumnos volvieron a sus casas familiares. Especialmente, en los estudios de videojuegos de la Universitat de Girona, suele haber alumnos de todo el estado, así que los alumnos participaban desde lugares como Galicia o Islas Canarias, por mencionar algunos. Cada uno de nosotros estábamos insertados en nuestra realidad particular. El reto era encontrar y potenciar un verdadero espacio de encuentro común a todos nosotros. Sentirnos parte. Se hizo lo que se pudo con las herramientas que teníamos, que por suerte eran muchas.

Por otra parte, se reformularon tareas y sistemas de evaluación para que fueran coherentes con la nueva forma de trabajo. Por ejemplo, el sketchbook que utilizábamos en clase para inventar personajes, entornos, objetos y otros elementos propios de los videojuegos, desembocó en un sketchbook tour formato ya existente y muy popular en las redes sociales. Nos adaptamos sin tener que inventar nada nuevo. Las herramientas y los formatos ya nos eran familiares.

No es nada extraño que alguno de los alumnos de clase sea YouTuber y elabore vídeos comentando gameplays, y muchos de ellos, y yo misma, somos consumidores de estos contenidos. Lo mismo ocurre con plataformas de streaming como Twitch que te permiten hacer o consumir sesiones en directo de temas muy diversos como pueden ser el desarrollo de videojuegos o sesiones de pintura.

Veamos a continuación el uso que hemos hecho de algunas de estas herramientas disponibles y gratuitas. 
NÚRIA PUIG BORRÀS: Herramientas digitales on line al servicio de los procesos de aprendizaje: comunicación, motivación y emociones.

@imgvideogames: Un blog colaborativo con los alumnos del Grado de Diseño y Desarrollo de Videojuegos. https://imgvideogame.wordpress.com

\section{imgvideogames}

Blog per compartir informació sobre videojocs. Aquest blog el va iniciar la primera promoció del Crau de Disseny i Desenvolupament de Videojocs de la UdC per l'assignatura Cultura Visual. Com que no podem fer classes presencials el recuperem. Segur que els companys de la primera promoció ens el deixen i si volen poden tornar a participar-hi.

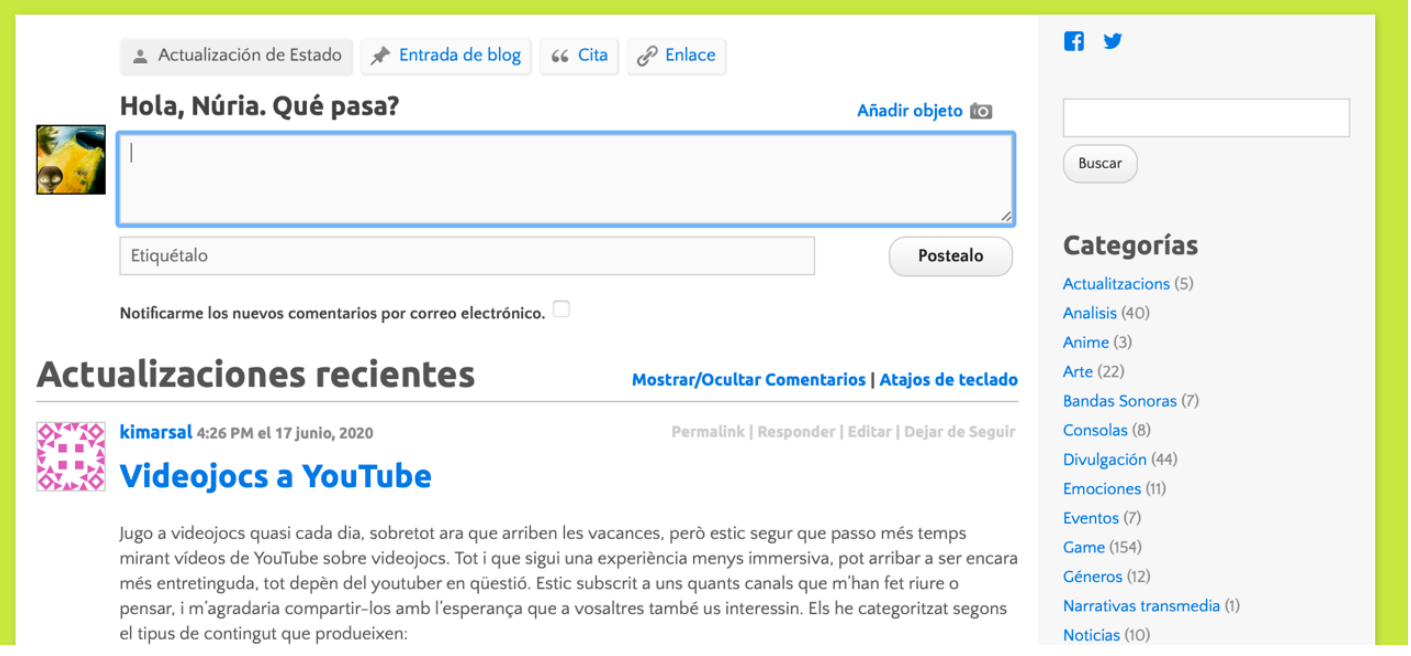

Este blog colaborativo se creó hace unos años con los alumnos de la primera promoción del Grado de Diseño y desarrollo de videojuegos. Fue planteado como una experiencia única que les pertenecía por su condición privilegiada de ser la primera promoción. La necesidad de replantear las herramientas del curso el mes de marzo de 2020 me hizo recurrir a esta plataforma creada por los alumnos de la primera promoción. Le cambiamos el diseño, dimos roles de colaborador a todos los miembros de la clase y empezamos a publicar entradas relacionadas con los contenidos de la asignatura. El blog nos proporcionó un espacio para publicar también comentarios que nos acercaban un poco más los unos a los otros. $Y$ además de las entradas individuales, los alumnos se responsabilizaban de algunos aspectos globales del blog.

Pinterest para referentes estéticos y videojuegos, https://www.pinterest.es/imgvideogame/

Otra plataforma que ya usábamos antes de la pandemia era Pinterest. Los referentes estéticos son importantes en nuestro aprendizaje. En este contexto, podemos crear tableros y colecciones de referentes, así como, algunas prácticas sobre temas específicos que requieren el análisis de elementos de los videojuegos, elementos de la sintaxis visual, referencias visuales que provienen de otros ámbitos de creación como el cómic, el cine o la pintura. Otra cosa interesante es que podemos observar los perfiles de los 
NÚRIA PUIG BORRÀS: Herramientas digitales on line al servicio de los procesos de aprendizaje: comunicación, motivación y emociones.

compañeros y el del profesor, e interactuar. Cada alumno crea su perfil con unos tableros comunes de la asignatura, como el Inspirational Mood o la Historia visual personal, y otros en función de sus gustos e intereses personales relacionados con la asignatura.

(D) Inicio Hoy Q Buscar

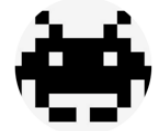

\section{Videogames Videojuegos}

@imgvideogame.Cultura visual y videojuegos.

161 seguidores : Siguiendo a 112

Mensaje Siguiendo

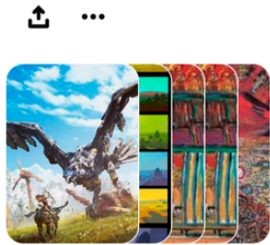

Todos los Pines

240 Pines $2 \mathrm{~d}$

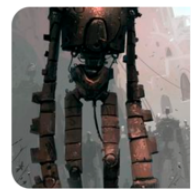

Robots 4 Pines
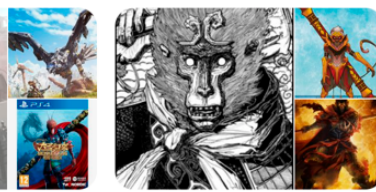

Sun Wu Kung. Trans... 16 Pines

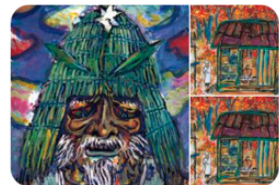

Run Akira Kurosawa ... 10 Pines

Con este perfil que vemos en la fotografía puedo interactuar con mis alumnos y publicar ejemplos relacionados con los contenidos que se desarrollan en clase.

\section{Tumbrl para la asignatura de Creatividad.}

\section{https://creativitat2020.tumblr.com}

\section{\#creativitat2020}

Si en la asignatura de Cultura Visual se desarrolló un blog entre todos los alumnos de clase. En la asignatura de Creatividad de los estudios de Publicidad y Relaciones Públicas, cada alumno desarrolló tres entornos blog dedicados a publicar y difundir sus trabajos.

En esta asignatura, tampoco es nada extraño utilizar herramientas digitales de creación y de difusión. De hecho, muchos de los trabajos realizados habitualmente ya eran propuestas para ser difundidas a través de sitios web o de redes sociales. Así pues no nos es ajeno trabajar con herramientas y plataformas digitales.

En la presecialidad, la comunicación interpersonal es muy fácil. Una mirada, unas risas, unos gestos, pueden ser grandes aliados para motivar los resortes necesarios en los procesos de aprendizaje. 
NÚRIA PUIG BORRÀS: Herramientas digitales on line al servicio de los procesos de aprendizaje: comunicación, motivación y emociones.

Este curso, marcado por las exigencias de la situación de pandemia, ha requerido llevar el uso de las herramientas digitales y las plataformas de difusión al extremo, éstas han proporcionado el espacio digital de encuentro entre alumnos y profesor y entre alumno y alumno. Los entornos digitales han substituido los encuentros presenciales. Nos hemos conocido menos o nos hemos conocido de forma distinta. Me ha costado más aprenderme los nombres de mis alumnos, y en muchos casos ahora los conozco por su nombre de usuario.

\section{CREA TIVITAT 2020}

En los oficios de la comunicación, gran parte de nuestra actividad profesional se realiza a través de estas formas de comunicación que requieren un medio técnico entre emisor y receptor. Como ya hemos dicho anteriormente, elementos esenciales en la definición de la comunicación de masas.

El balance de la experiencia hay que hacerlo sin compararlo con el pasado. Ver las cosas que hemos aprendido, más que aquellas que hemos perdido, que esperamos pronto podamos recuperar. Más allá de sentimentalismos podemos valorar las competencias que hemos trabajado y las competencias que hemos trasladado al plano digital. A pesar de todo, hemos podido trabajar las competencias relacionadas con la creatividad, con el trabajo en equipo, con la mejora de lenguajes visuales, con la adquisición de conocimientos a través de lecturas de publicaciones especializadas.

Hemos puesto en práctica el uso colaborativo de aplicaciones como GitMind y otras aplicaciones similares, que con sus limitaciones, nos han permitido elaborar, por ejemplo, mapas mentales a distancia y de forma colaborativa.

Nos hemos mantenido disciplinados, hemos aprendido a gestionar un poco mejor nuestras emociones para concentrarnos en nuestras tareas. Hemos indagado en los procesos creativos des de una perspectiva individual muy necesaria para mejorar nuestra eficacia creadora. $\mathrm{Y}$ todo esto mis alumnos lo han hecho en un contexto global y personal como mínimo complejo. Esta experiencia educativa solamente ha sido posible por el elevado grado de implicación de todos los alumnos que han participado en ella.

Este curso 2020-21 en la asignatura de Creatividad de tercer curso de los estudios de Publicidad y Relaciones Públicas de la Universitat de Girona hemos trabajado con diferentes plataformas digitales:

1. Moodle (organización temporal de contenidos y materiales, comunicación a través de avisos y noticias). 
NÚRIA PUIG BORRÀS: Herramientas digitales on line al servicio de los procesos de aprendizaje: comunicación, motivación y emociones.

2. Black Board Collaborate (sesiones no presenciales de clase y tutorías on line)

3. Blogs TUMBRL (plataformas de trabajo, desarrollo, diseño y difusión)

En este artículo nos interesa la experiencia creativa que hemos desarrollado en la plataforma TUMBRL.
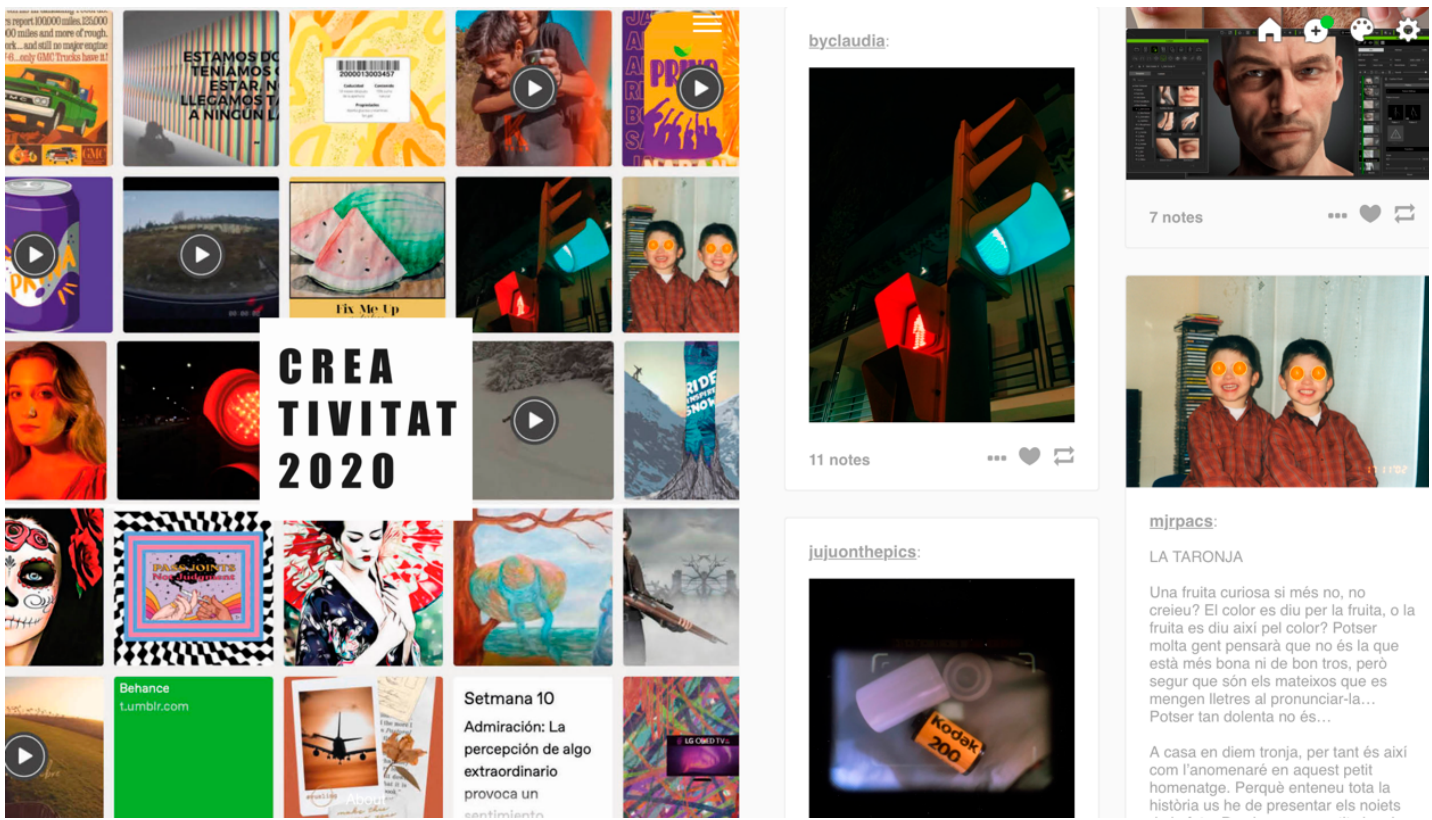

mirpacs
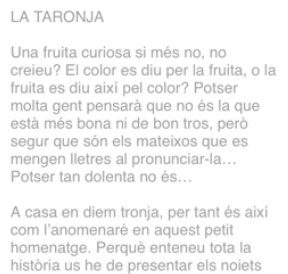

Este blog, https://creativitat2020,tumblr.com, lo he creado y utilizado para rebloguear algunos de los trabajos realizados en el marco de la asignatura y quiere contribuir a difundir los trabajos y poner en valor las aportaciones de los blogs individuales.

Los datos generados tanto por los blogs de los alumnos como el de la profesora también nos han proporcionado datos para evaluar la experiencia y la implicación de los alumnos en la propuesta educativa. La plataforma nos proporciona datos sobre el número de blogs, las visitas, los comentarios o los seguidores. Todas las estadísticas generadas, aunque podrían darnos una idea de la magnitud de las interacciones y del engagement, no nos interesan demasiado en este artículo, aunque han formado parte del sistema de evaluación de los alumnos ya que un porcentaje de su nota provenía de la evaluación de este engagement. El objetivo de la utilización de cualquier herramienta ha sido mejorar la cantidad y la calidad de nuestras interacciones y de nuestra comunicación interpersonal forzosamente mediada.

Hemos trabajado con la etiqueta \#creativitat2020 que nos permite encontrar con más facilidad los trabajos realizados. Con la intención de promover la comunicación entre los miembros de una clase, este curso contaba con 80 alumnos, cada alumno ha realizado 3 blogs:

1. Proyecto personal. En este blog cada uno ha desarrollado su proyecto creativo personal.

2. Prácticas de la asignatura. En este blog cada alumno ha publicado las prácticas de la asignatura. 
NÚRIA PUIG BORRÀS: Herramientas digitales on line al servicio de los procesos de aprendizaje: comunicación, motivación y emociones.

3. Referentes (reblogs, publicación de otros trabajos). En este blog cada alumno ha reblogueado "cosas que le gustaban" con la intención de aumentar los referentes.

Los criterios de evaluación han observado la realización y la calidad de las prácticas individuales, la ideación y nivel de creatividad, elaboración y difusión del proyecto personal, el diseño de los blogs, la interacción y el engagement conseguido.

\section{Plataformas para mantenerse en contacto y mejorar la calidad de la comunicación.}

Estas plataformas nos han permitido estar en contacto permanente entre todos los miembros de la clase. La utilización de los mensajes personales y reacciones a las publicaciones ha dotado de más rapidez y fluidez a la comunicación entre todos nosotros. Un aspecto que se ha visto mermado al trabajar a distancia.

No todo es bonito. Algunos de mis alumnos me comentan que es difícil mantener la atención en algunas clases on line cuando éstas no son participativas. Otros alumnos me comentan que se sienten solos frente a una gran cantidad de tareas. Al cansancio pandémico debemos sumar la cantidad de horas que pasamos todos frente al ordenador. No es difícil ser empática con los alumnos ya que a los profesores nos pasa lo mismo. Por otra parte, participar cuando una clase se está gravando no invita a los más tímidos o introvertidos a participar. El otro día pactamos que las clases participativas en las que compartimos y comentamos los trabajos realizados por los alumnos no se gravan, lo cual supone crear un espacio más cómodo que invita más a la participación.

Finalmente, destacar de nuevo que estas experiencias educativas solamente pueden llegar a buen puerto con la buena actitud, la colaboración y la motivación de los alumnos. Más todavía en una situación no deseada a la cual hemos tenido que adaptarnos todos de forma rápida y con situaciones personales individuales distintas $y$, a veces, complejas.

Para ser justa, debo decir que si alguna cosa ha funcionado en estos días de trabajo online ha sido, sobre todo, gracias a la disciplina de mis alumnos. Sin su madura y entusiasta respuesta nada de lo propuesto habría funcionado. $Y$ espero que aquellos que en algún momento se hubieran podido ver superados por la situación puedan haber encontrado en estas pequeñas ágoras un espacio reconfortante.

Para todos ellos mi enorme agradecimiento. 
NÚRIA PUIG BORRÀS: Herramientas digitales on line al servicio de los procesos de aprendizaje: comunicación, motivación y emociones.

\section{REFERENCIAS}

https://creativitat2020.tumblr.com

https://imgvideogame.wordpress.com

https://www.pinterest.es/imgvideogame/

Mena-Young, Margoth (2018): Retos docentes en ambientes virtuales: del modelo a distancia al entorno virtual en un posgrado en Comunicación. Communication Papers, 2018, Vol.7 - Num. 14, pp.107/122. Universitat de Girona. Girona.

Sugata Mitra (2021): La escuela en la nube. Título original: The School in the Cloud, Ediciones Paidós. Sugata Mitra (2005): The Hole in the Wall: Self Organising Systems in Education. TED Books, English Edition.

\section{CURRICULUM VITAE . NÚRIA PUIG BORRÀS}

Profesora de Comunicación en la Universidad de Girona. Dra. Derecho, economía y empresa (Universitat de Girona) con una tesis sobre publicidad y emociones (2011). Licenciada en Ciencias de la Información. Publicidad y Relaciones Públicas por la Universitat Autònoma de Barcelona (1992). Actualmente es Profersora Asociada de Creatividad en los Estudios de Publicidad y Relaciones Públicas, y de Cultura Visual en el Grado de Diseño y Desarrollo de Videojuegos en la Universidad de Girona. Anteriormente, Coordinadora del servicio de estudios y publicaciones del Centre d'Investigació de la Comunicació CEDIC (1993-1997). Responsable de investigación y publicaciones del Consell de l'Audiovisual de Catalunya CAC (1997-2001). Profesora de Proyectos y Empresa informativa del Departamento de Periodismo de la Facultad de Ciencias de la Comunicación de la UAB (1994-2003); y de Medios de Comunicación de Masas e Industria de la Publicidad en los estudios de Periodismo y Publicidad de la Universidad Abatoliba (20042007). En la actualidad, desarrolla su actividad profesional en el ámbito del diseño gráfico y las redes sociales. Compagina la actividad académica con la pintura. Algunos de sus intereses giran alrededor de la experimentación y la docencia de la creatividad, los procesos artísticos, los lenguajes plásticos, las imágenes digitales o el estudio de las artes plásticas y la lengua chinas. 